\title{
Effects of neck stabilization and dynamic exercises on pain, disability and fear avoidance beliefs in patients with non-specific neck pain; a randomized clinical trial
}

\author{
Bashir Kaka ${ }_{\text {ABDEFG, }}$ Omoyemi O. Ogwumike ${ }_{\text {ABDE, }}$ Samuel O. Ogunlade ${ }_{\text {ABDE }}$ and Ade F. Adeniyi ${ }_{\text {ACDF }}$ \\ ${ }^{1}$ Department of Physiotherapy, Faculty of Allied Health Sciences, College of Health Sciences, \\ Bayero University, P.M.B 3011, Kano, Nigeria \\ ${ }^{2}$ Department of Physiotherapy, Faculty of Clinical Sciences, College of Medicine, University of \\ Ibadan, Ibadan, Nigeria \\ ${ }^{3}$ Department of Orthopaedic and Trauma, Faculty of Clinical Sciences, College of Medicine, \\ University of Ibadan, Nigeria
}

\begin{abstract}
Background: Non-specific neck pain (NsNP) constitutes a great burden to individuals in the populace and major challenge to physiotherapists. This study aims at evaluating the effects of stabilization and dynamic exercises on pain intensity, disability and fear avoidance beliefs in patients with NsNP.

Material and Methods: Eighty eight patients with NsNP participated in this single-blind randomized controlled trial. The participants were assigned to one of three groups; the Stabilization Group, Stabilization plus Dynamic Exercise Group and Dynamic Exercise Group using fish bowl technique. Treatment was applied three times weekly for 8 weeks and outcomes were measured in terms of pain intensity, disability and fear avoidance beliefs at the end of 4th and 8th week of study. Data were analyzed using descriptive and inferential statistics, at $\mathrm{p}=0.05$.
\end{abstract}

Results: Seventy six participants with mean age $46.82 \pm 12.43$ years completed the study. The groups were comparable in baseline outcome measures ( $>0.05$ ). Within-group comparison across the three time-points of the study revealed that the different treatment regimens had significant effects on all the outcome measures $(p<0.05)$. There were significant differences between the three groups at week 4 and 8 respectively. Post-hoc analysis showed that Stabilization had higher reductions in pain, disability and fear avoidance beliefs at week 4 and 8 of the study respectively.

Conclusion: Stabilization exercises alone as well as stabilization plus dynamic or dynamic exercises are effective. However stabilization exercises resulted in better reduction in pain intensity, functional disability and fear avoidance beliefs in participants with non-specific neck pain.

Keywords: Neck pain, Stabilization exercises, Neck disability, Dynamic Exercises,

\section{Introduction}

Neck pain is an unpleasant sensory experience in the neck which may be manifested as fatigue, tension or pain that radiates to the shoulders, upper extremities or head [1]. Non-specific Neck Pain (NsNP) refers to neck pain (with or without radiation) whose underlying cause cannot be traced to any specific systemic disease [2]. Nonspecific neck pain may be attributed to numerous structures in the neck and surrounding regions, such as the muscles, joint structures, ligaments, intervertebral disks, and neural structures [3].

Neck pain appears to be a common ailment all over the world. It is a public health problem associ- 
ated with significant disability $[4,5]$. The lifetime prevalence has been reported to be between $14.2 \%$ and $70 \%$. The one-year prevalence of neck pain among adults ranges from $12.1 \%$ to $71.5 \%$ while the point prevalence is reported to be between $12 \%$ and 34\% [5]. In Nigeria, neck pain is becoming a common problem, probably due to more frequent use of electronic gadgets such as computers, mobile phones, android tablets and the like [6] particularly among the young population. It is seen often in our clinical setting and constitutes a significant burden on the physiotherapy care facilities [7]. The lifetime, one-year and point prevalence of neck pain in the rural community in North western Nigeria were $67.9 \%, 65.9 \%$ and $17.0 \%$ respectively [8].

Exercise programmes for managing neck pain differ with regard to duration, training frequency, intensity, and mode of exercise. Stabilisation exercises are exercises that are meant to maximize function, and prevent injury progression or re-injury. They require coordination and training of the anterior and posterior cervical and shoulder girdle musculatu[9].

Dynamic Neck Exercises is progressive-resistive strength training that involves movement of other parts of the body and neck [10]. Strengthening exercises involve any exercise done by the individual/patient that includes resistance, for example isometric, isokinetic or isotonic. It could include strength training with machines [11], thera-band, free weights, or low load endurance exercises to train muscle control [12].

Cochrane review on the effect of exercises for nonspecific neck disorders concluded that the summarized evidence indicates that exercises have a role in the treatment of acute and chronic non-specific neck pain but that the relative benefit of each type of exercise needs to be studied extensively [13]. The aim of this study was to investigate the effects of eight weeks of neck stabilisation and dynamic exercises on pain intensity, functional disability and fear avoidance beliefs in patients with non-specific neck pain.

\section{Material/Methods}

This study employed a single blinded randomized controlled clinical trial design, registered with Pan Africa Clinical Trial Registry PACTR 201402000727807. Consecutive sampling technique was used to recruit participants for the study as they become available. The subjects were screened to determine whether they met the inclusion criteria for the study. The participants for this study were patients with non-specific neck pain with chronic neck pain, who were able to comprehend instruction in English or Hausa language, who were not involved in any other form of exercise training during the course of the study.

The following categories of patients were excluded from the study: Patients with co-morbidities that influence overall well-being, for example AIDS, Patients with specific disorders of the cervical spine, such as; disk prolapse, spinal stenosis, postoperative conditions, history of severe trauma, spasmodic torticollis, frequent migraine, fibromyalgia, shoulder diseases, inflammatory rheumatic diseases and psychiatric illness, Patients with obvious spinal deformity or neurological disease, Patients with a reported history of cardiovascular diseases contraindicated to exercise and Patients below 18 years.

They were recruited from the National Orthopaedic Hospital, Dala, Kano. The consented participants were randomly allocated into the three study groups viz. neck stabilization exercise group (NSEG; $\mathrm{n}=30$ ); neck stabilization plus dynamic exercise group (NSDEG; $\mathrm{n}=29$ ); or neck dynamic exercise group (NDEG; $n=29$ ). However seventy six participants completed the study NSEG; $\mathrm{n}=27$, NSDEG; $\mathrm{n}=25$, NSDEG; $\mathrm{n}=24$ as shown in figure 1 flow chart. Ethical approval for the study was sought and obtained from ethics committee of National Orthopaedic Hospital, Dala, Kano (NOHD/RET/ETHIC/60). 


\section{Instruments}

The following instruments were used to collect data during the course of carrying out this study:

1. Biodata form: This was used to obtain socio-demographic information of participants.

2. Neck Disability Index Questionnaire: This questionnaire was used to assess activity limitation and participation restriction of the participants

\section{Fear-Avoidance Belief Questionnaire} (FABQ): This is a 16-item questionnaire that was used to measure participants' fear of pain.

4. Visual Analogue Scale (VAS): This scale was used to assess pain severity in participants.

5. Thera-band: (Theraband, Hygiene Corp., Akron, $\mathrm{OH}$ ) was used for dynamic strengthening exercises.

\section{Treatment}

\section{Neck stabilization exercises}

The neck stabilization exercise training is designed to restore cervical muscle endurance and coordination $[14,15,16]$. All the participants in this group performed the following exercises

Chin tuck

In standing position, participant pulls back the chin (as if trying to make a double chin) while keeping the eyes level. This was done for 15 repetitions.

\section{Cervical extension}

In standing position, participant grasps the base of the neck, with both hands while extending the neck as far as possible. This was done for 15 repetitions.

\section{Shoulder shrugs}

In standing position, participant shrugs the shoulders, bringing them up towards the ears. This was done for 15 repetitions.

\section{Shoulder rolls}

In standing position, participant rolls the shoulders forward in a circle. Then, rolls the shoulders backwards in a circle. Then participant relaxes and repeats the procedure for 15 times.

\section{Scapular retraction}

In standing position, participant brings the shoulder blades together in the back; participant then relaxes and repeats the procedure for 15 times $[14,15,16]$.

\section{Neck dynamic exercises}

Dynamic exercises training are aimed at increasing muscle strength [17]. The progression of exercises was done using different colours of Thera-band indicating varied resistance.

Participants started with the Thera-band with the least resistance, coloured red, and progressed to those with increasingly greater resistance, green then blue. During the exercises, elongation was encouraged to be maintained at $100 \%$.

\section{Cervical extension-dynamic isometric (sitting)}

The participant sits in an upright position and one end the loop of thera-band is attached to the participant's head and the other end to a sturdy stand. The participant bends forward, then holds and slowly returns to the starting position, keeping the spine posture erect throughout the exercise. This is done for 15 repetitions in either direction $[18,17,19]$.

\section{Cervical Flexion-Dynamic isometric (sitting)}

The participant sits in an upright position and backs a sturdy stand. One end of a loop of theraband is securely attached to the sturdy stand and the other to the participant's head. The participant bends forward, then holds and slowly returns to the starting position, keeping the spine posture erect throughout the exercise. The number of repetitions is 15 in each direction $[18,17,19]$.

\section{Chest flies exercises (standing position)}

With the participant in standing position, the middle of the thera-band is fastened securely to a sturdy stand at shoulder level. The participant backs the sturdy stand, with one leg slightly in front of the other. The participant then grasps the bands at shoulder height with the elbows straight, 
and pulls bands inward with palms facing each

other and then slowly returns. This was done 15 times in each direction [20,17,21].

Frequency: Stabilization and dynamic exercise sessions were held three times a week on alternate days for eight weeks each lasting approximately 45 minutes. Altogether, each participant had 24 treatment sessions.

\section{Data Analysis}

Descriptive statistics of mean, standard deviation, median, interquartile range and percentages were used to summarize all data obtained from the participants. Analysis of Variance (ANOVA) was used to compare pain intensity at baseline, fourth and eight weeks of the study in the three groups - NSEG, NSDEG and NDEG. Repeated measures ANOVA was used for within group comparison of the effects of the NSEG, NSDEG and NDEG on pain intensity. LSD post-hoc multiple comparisons analysis was used to test for any significant difference found in the F-ratios. Friedman's ANOVA was used for withingroup comparison of the effects of the different treatment programmes on the NDI and FAB, scores. Kruskal Wallis test was used to compare the neck disability index scores (NDI) and fear avoidance beliefs scores (FAB), at baseline, fourth and eight weeks of the study in the different treatment groups. Wilcoxon signed ranked test was used as the post-hoc multiple comparisons to test for any significant difference found. Alpha level was set at 0.05 . The data analyses were carried out using the SPSS version 18.0 (SPSS Inc., Chicago, Illinois, USA).

\section{Results and discussion}

\section{Characteristics of participants}

Eighty-eight participants were recruited for this study. Seventy-six of the participants completed the eight week programme: NSEG, $\mathrm{n}=27$; NSDEG, $\mathrm{n}=25$; NSDEG, $\mathrm{n}=24$. Participants' ages ranged from 22 to 67 years, mean $46.8 \pm 12.43$ years. Seventy $(74.5 \%)$ were married and $68(77.3 \%)$ were from the Hausa/Fulani tribe. These can be observed in table 1 . 
Table 1. Participants Socio-demographic Characteristics

\begin{tabular}{|c|c|c|}
\hline Variable & $\mathbf{n}$ & $\%$ \\
\hline \multicolumn{3}{|l|}{ Gender } \\
\hline Male & 42 & 47.7 \\
\hline Female & 46 & 52.3 \\
\hline \multicolumn{3}{|l|}{ Marital status } \\
\hline Single & 18 & 20.5 \\
\hline Married & 70 & 79.5 \\
\hline \multicolumn{3}{|l|}{ Tribe } \\
\hline Hausa/Fulani & 68 & 77.3 \\
\hline Yoruba & 10 & 11.4 \\
\hline Igbo & 5 & 5.7 \\
\hline Others & 5 & 5.7 \\
\hline \multicolumn{3}{|c|}{ Educational qualification } \\
\hline Nil & 6 & 6.8 \\
\hline Primary/ Secondary & 55 & 62.5 \\
\hline Tertiary & 27 & 30.7 \\
\hline \multicolumn{3}{|l|}{ Employment } \\
\hline Unemployed & 19 & 21.6 \\
\hline Self-employed & 47 & 53.5 \\
\hline Government employed & 22 & 25.0 \\
\hline \multicolumn{3}{|l|}{ Income per month } \\
\hline Low/Middle & 41 & 46.6 \\
\hline Moderate/High & 47 & 53.4 \\
\hline \multicolumn{3}{|l|}{ Pain duration in weeks } \\
\hline $6-8$ & 19 & 21.6 \\
\hline $9-12$ & 64 & 72.7 \\
\hline 13 and above & 5 & 5.7 \\
\hline
\end{tabular}

\section{Within-group comparison}

\section{Pain intensity}

With the aid of repeated measures ANOVA, within-group comparison of participants' pain scores in different groups were made across the baseline, the 4 th and 8 th weeks of the study as shown in table 2.

Table 2. Comparisons of mean pain intensity scores among participants across the 3 time points of the study by treatment

\begin{tabular}{|c|c|c|c|c|c|}
\hline Group & Baseline & 4 Weeks & 8 Weeks & F-ratio & $\mathrm{P}$ \\
\hline & $\overline{\mathrm{X}} \pm \mathrm{SD}$ & $\overline{\mathrm{X}} \pm \mathrm{SD}$ & $\overline{\mathrm{X}} \pm \mathrm{SD}$ & & \\
\hline NSEG & $\begin{array}{c}7.48 \pm 1.62^{*} \\
(\mathrm{n}=30)\end{array}$ & $\begin{array}{r}4.77 \pm 1.98^{\#} \\
(\mathrm{n}=27)\end{array}$ & $\begin{array}{r}2.66 \pm 1.27^{\S} \\
\quad(\mathrm{n}=27)\end{array}$ & 102.069 & $(<0.05)$ \\
\hline NSDEG & $\begin{array}{c}6.92 \pm 1.32^{*} \\
(\mathrm{n}=29)\end{array}$ & $\begin{array}{c}5.64 \pm 1.68^{\#} \\
(\mathrm{n}=25)\end{array}$ & $\begin{array}{c}4.48 \pm 1.38^{\mathrm{s}} \\
(\mathrm{n}=25)\end{array}$ & 56.711 & $(<0.05)$ \\
\hline NDEG & $\begin{array}{c}7.04 \pm 1.26^{*} \\
(\mathrm{n}=29)\end{array}$ & $\begin{array}{l}5.79 \pm 1.4^{\#} \\
\quad(\mathrm{n}=25)\end{array}$ & $\begin{array}{r}4.12 \pm 0.89^{\mathrm{s}} \\
\quad(\mathrm{n}=24)\end{array}$ & 65.867 & $(<0.05)$ \\
\hline
\end{tabular}

\section{Alpha level was set at 0.05}

$$
\begin{array}{r}
7.04 \pm 1.26 \\
(\mathrm{n}=29)
\end{array}
$$$$
(\mathrm{n}=25)
$$

Superscripts $(*, \#, \$)$ for a particular variable: Mean values with different superscripts are significantly different; Mean values with the same superscripts are not significantly different.

Key:

$$
\begin{array}{ll}
\text { VAS }= & \text { Visual Analogue Scale } \\
\text { NSEG }= & \text { Neck stabilization exercises group }
\end{array}
$$

NSDEG $=$ Neck stabilization plus dynamic exercises group

NDEG $=$ Neck dynamic exercises group

$\mathrm{n}=\quad$ Number of participants in the group 


\section{Functional disability}

Within-group comparison of functional disability using the neck disability index scores of participants in the different groups was done with the aid of Friedman's ANOVA across the baseline, 4th and 8th week of the study as shown in table 3.

Table 3. Comparison of median neck disability scores among participants across the 3 time points of the study by

\begin{tabular}{cccccc} 
treatment group & & & \\
Group & Baseline & 4 Weeks & 8 Weeks & $X^{2}$ & P value \\
& Median(IQR) & Median(IQR) & Median(IQR) & & \\
\hline NSEG & $\begin{array}{c}21.0(4.5)^{*} \\
(\mathrm{n}=30)\end{array}$ & $\begin{array}{c}18.0(7.0)^{\#} \\
(\mathrm{n}=27)\end{array}$ & $\begin{array}{c}14.0(6.7)^{\S} \\
(\mathrm{n}=27)\end{array}$ & 19.82 & $(<0.05)$ \\
NSDEG & $\begin{array}{c}20.0(6.5)^{*} \\
(\mathrm{n}=29)\end{array}$ & $\begin{array}{c}16.0(7.5)^{\#} \\
(\mathrm{n}=25)\end{array}$ & $\begin{array}{c}14.0(6.5)^{\S} \\
(\mathrm{n}=25)\end{array}$ & 17.61 & $(<0.05)$ \\
NDEG & $\begin{array}{c}23.5(8.5)^{*} \\
(\mathrm{n}=29)\end{array}$ & $\begin{array}{c}15.0(2.0)^{\#} \\
(\mathrm{n}=25)\end{array}$ & $\begin{array}{c}12.0(2.0)^{\#} \\
(\mathrm{n}=24)\end{array}$ & 50.64 & $(<0.05)$
\end{tabular}

Alpha level was set at 0.05

Superscripts $(*, \#, \$)$ for a particular variable: Median values with different superscripts are significantly different; Median values with the same superscripts are not significantly different.

Key:

$\begin{array}{lll}\mathrm{NSEG}= & \text { Neck stabilization exercises group } \\ \mathrm{NSDEG}= & \text { Neck stabilization plus dynamic exercises group } \\ \mathrm{NDEG}= & \text { Neck dynamic exercises group } \\ \mathrm{n} & = & \text { Number of participants in the group } \\ \mathrm{IQR} & = & \text { Inter-Quartile Range }\end{array}$

\section{Fear avoidance beliefs}

Within-group comparison of the fear avoidance beliefs scores of participants in the different groups was made with the aid of Friedman's ANOVA, across the baseline, 4th and 8th week of the study as shown in table 4 . 
Table 4. Comparison of median domain and total scores on fear avoidance beliefs (FAB) among participants across the 3 time points of the study by treatment group

\begin{tabular}{|c|c|c|c|c|c|}
\hline Group & $\begin{array}{c}\text { Baseline } \\
\text { Median(IQR) }\end{array}$ & $\begin{array}{c}4 \text { Weeks } \\
\text { Median(IQR) }\end{array}$ & $\begin{array}{c}8 \text { Weeks } \\
\text { Median(IQR) }\end{array}$ & $\mathrm{X}^{2}$ & $\mathrm{P}$ \\
\hline $\begin{array}{l}\text { NSEG } \\
\text { Physical activity }\end{array}$ & $16.0(3.5)^{*}$ & $12.0(5.0)^{\#}$ & $10.0(8.0)^{\mathrm{s}}$ & 14.47 & $(<0.05)$ \\
\hline Work & $24.0(10.0)^{*}$ & $13.0(6.0)^{\#}$ & $14.0(9.0)^{\#}$ & 24.92 & $(<0.05)$ \\
\hline Total & $\begin{array}{c}41.0(7.5)^{*} \\
(n=30)\end{array}$ & $\begin{array}{l}28.0(10.0)^{\#} \\
\quad(n=27)\end{array}$ & $\begin{array}{c}22.0(9.0)^{\#} \\
(n=27)\end{array}$ & 30.68 & $(<0.05)$ \\
\hline NSDEG & & & & & \\
\hline Physical activity & $15.0(3.5)^{*}$ & $13.0(7.5)^{\#}$ & $12.0(6.0)^{\#}$ & 12.23 & $(<0.05)$ \\
\hline Work & $24.0(10.0)^{*}$ & $21.0(9.0)^{\#}$ & $19.5(10.5)^{\#}$ & 26.33 & $(<0.05)$ \\
\hline Total & $\begin{array}{c}40.0(9.5)^{*} \\
(n=29)\end{array}$ & $\begin{array}{c}34.0(10.0)^{\#} \\
(n=25)\end{array}$ & $\begin{array}{l}30.0(14.5)^{\$} \\
\quad(n=25)\end{array}$ & 24.00 & $(<0.05)$ \\
\hline $\begin{array}{l}\text { NDEG } \\
\text { Physical activity }\end{array}$ & $15.0(4.0)^{*}$ & $14.0(5.0)^{\#}$ & $12.0(8.0)^{\$}$ & 50.64 & $(<0.05)$ \\
\hline Work & $23.0(8.0)^{*}$ & $21.0(6.5)^{\#}$ & $19.5(5.8)^{\$}$ & 46.32 & $(<0.05)$ \\
\hline Total & $\begin{array}{l}40.0(11.3)^{*} \\
\quad(n=29)\end{array}$ & $\begin{array}{l}35.0(7.0)^{\#} \\
(\mathrm{n}=25)\end{array}$ & $\begin{array}{c}30.5(7.8)^{\$} \\
(\mathrm{n}=24)\end{array}$ & 49.58 & $(<0.05)$ \\
\hline
\end{tabular}

Alpha level was set at 0.05

Superscripts $(*, \#, \$)$ for a particular variable: Median values with different superscripts are significantly different; Median values with the same superscripts are not significantly different.

Key

$\begin{array}{lll}\text { NSEG } & = & \text { Neck stabilization exercises group } \\ \text { NSDEG }= & \text { Neck stabilization plus dynamic exercises group } \\ \text { NDEG }= & \text { Neck dynamic exercises group } \\ \mathrm{n} & = & \text { Number of participants in the group } \\ \mathrm{IQR} & = & \text { Inter-Quartile Range }\end{array}$

\section{Between-groups comparison}

\section{Pain intensity}

With the aid of the One-way ANOVA table 5 shows the comparison of pain intensity of participants in the NSEG, NSDEG, and NDEG at the baseline and at the end of the 4th and 8th week of the study. 
Table 5. Comparison of participants mean pain intensity scores using the Visual Analogue Scale by treatment group at baseline, 4th and 8th week of the study

\begin{tabular}{|c|c|c|c|c|c|c|c|c|c|}
\hline Group & $\begin{array}{l}\text { Baseline } \\
\text { Mean+ SD }\end{array}$ & $\mathrm{F}$ & $\mathrm{P}$ & $\begin{array}{l}4 \text { week } \\
\text { Mean + SD }\end{array}$ & $\mathrm{F}$ & $\mathrm{P}$ & $\begin{array}{l}8 \text { week } \\
\text { Mean }+ \text { SD }\end{array}$ & $\mathrm{F}$ & $\mathrm{P}$ \\
\hline NSEG & $\begin{array}{l}7.48 \pm 1.62 \\
(n=30)\end{array}$ & & & $\begin{array}{l}4.77 \pm 1.27^{*} \\
(n=27)\end{array}$ & & & $\begin{array}{l}2.66 \pm 1.27^{*} \\
(n=27)\end{array}$ & & \\
\hline NSDEG & $\begin{array}{l}6.92 \pm 1.32 \\
(n=29)\end{array}$ & 0.135 & 0.71 & $\begin{array}{l}5.64 \pm 1.68^{\#} \\
(\mathrm{n}=25)\end{array}$ & 9.79 & $(<0.05)$ & $\begin{array}{l}4.48 \pm 1.38^{\#} \\
(\mathrm{n}=25)\end{array}$ & 10.83 & $(<0.05)$ \\
\hline NDEG & $\begin{array}{l}7.04 \pm 1.62 \\
(n=29)\end{array}$ & & & $\begin{array}{l}5.76 \pm 1.41^{\#} \\
(\mathrm{n}=25)\end{array}$ & & & $\begin{array}{l}4.12 \pm 0.89^{\#} \\
(n=24)\end{array}$ & & \\
\hline
\end{tabular}

Alpha level was set at 0.05

Superscripts $(*, \#, \$)$ for a particular variable: Mean values with different superscripts are significantly different; Mean values with the same superscripts are not significantly different.

Key: $\quad$ NSEG $=$ Neck stabilization exercises group

NSDEG $=\quad$ Neck stabilization plus dynamic exercises group

$\mathrm{NDEG}=\quad$ Neck dynamic exercises group

$\mathrm{n}=$ number of participants in the group

$\mathrm{SD} \quad=\quad$ standard deviation

\section{Functional disability}

With the aid of the Kruskal-Wallis test, comparisons of the neck disability index scores of the NSEG, NSDEG, and NDEG of participants were made at the baseline, and the end of 4th and 8 th week of the study as shown in table 6 .

Table 6. Comparison of median neck disability scores of participants by treatment group at 0,4 and 8 week of the study

\begin{tabular}{|c|c|c|c|c|c|c|c|c|c|}
\hline Group & $\begin{array}{l}\text { Baseline } \\
\text { M e d i a n } \\
\text { (IQR) }\end{array}$ & $\mathrm{H}$ & $\mathrm{P}$ & $\begin{array}{l}4 \text { weeks } \\
\text { M e d i a n } \\
\text { (IQR) }\end{array}$ & $\mathrm{H}$ & $\mathrm{P}$ & $\begin{array}{l}8 \text { weeks } \\
\text { M e d i a n } \\
\text { (IQR) }\end{array}$ & $\mathrm{H}$ & $\mathrm{P}$ \\
\hline NSEG & $\begin{array}{l}21.0(4.5) \\
(n=30)\end{array}$ & & & $\begin{array}{l}18.0(7.0) \\
(\mathrm{n}=27)\end{array}$ & & & $\begin{array}{l}12.0\left(2.0^{*}\right. \\
(\mathrm{n}=27)\end{array}$ & & \\
\hline NSDG & $\begin{array}{l}20.0(6.5) \\
(n=29)\end{array}$ & 9.70 & 0.71 & $\begin{array}{l}16.0(7.5) \\
(\mathrm{n}=25)\end{array}$ & 6.71 & 0.56 & $\begin{array}{l}14.0(6.5)^{\#} \\
(25)\end{array}$ & 16.20 & $(<0.05)$ \\
\hline NDEG & $\begin{array}{l}22.0(7.5) \\
(\mathrm{n}=29)\end{array}$ & & & $\begin{array}{l}15.0(7.5) \\
(\mathrm{n}=25)\end{array}$ & & & $\begin{array}{l}14.0(6.7)^{\#} \\
(24)\end{array}$ & & \\
\hline
\end{tabular}

Alpha level was set at 0.05

Superscripts $(*, \#, \$)$ for a particular variable: Median values with different superscripts are significantly different; Median values with the same superscripts are not significantly different.

Key:

$\begin{array}{lll}\text { NSEG } & = & \text { Neck stabilization exercises group } \\ \text { NSDEG } & \text { Neck stabilization plus dynamic exercises group } \\ \text { NDEG } & = & \text { Neck dynamic exercises group } \\ \mathrm{n} & = & \text { Number of participants in the group } \\ \mathrm{H} & = & \text { Kruskal-Wallis value } \\ \text { IQR } & = & \text { Inter-Quartile Range }\end{array}$




\section{Fear avoidance beliefs}

With the aid of the Kruskal-Wallis test, between group comparisons of fear avoidance beliefs were made as showed in table 7.

Table 7. Comparison of median fear avoidance beliefs total scores of participants by treatment group at the 0 , 4 th and 8th week of the study.

\begin{tabular}{|c|c|c|c|c|c|c|c|c|c|c|}
\hline Group & $\begin{array}{l}0 \text { week } \\
\text { Median (IQR) }\end{array}$ & $\mathrm{H}$ & $\mathrm{P}$ & $\begin{array}{l}4 \text { week } \\
M \text { e d i a n } \\
\text { (IQR) }\end{array}$ & $\mathrm{H}$ & $\mathrm{P}$ & $\begin{array}{l}8 \text { week } \\
\text { M e d i a n } \\
\text { (IQR) }\end{array}$ & $\mathrm{H}$ & $\mathrm{P}$ & \\
\hline NSEG & $\begin{array}{l}41.0(7.5) \\
(\mathrm{n}=30)\end{array}$ & & & $\begin{array}{l}28.0(10.0)^{*} \\
(\mathrm{n}=27)\end{array}$ & & & $\begin{array}{l}22.0(9.0)^{*} \\
(\mathrm{n}=27)\end{array}$ & & & \\
\hline NSDEG & & $\begin{array}{l}40.0(9.5) \\
(n=29)\end{array}$ & 2.78 & 0.25 & $\begin{array}{r}34.0(10.0)^{*} \\
(\mathrm{n}=25)\end{array}$ & 15.431 & 0.01 & $\begin{array}{l}30.0(14.5)^{\#} \\
(25)\end{array}$ & 17.66 & 0.01 \\
\hline NDEG & $\begin{array}{c}40.0(11.25) \\
(\mathrm{n}=29)\end{array}$ & & & $\begin{array}{l}35.0(7.0)^{\#} \\
(\mathrm{n}=25)\end{array}$ & & & $\begin{array}{l}30.5(7.8)^{\#} \\
(24)\end{array}$ & & & \\
\hline
\end{tabular}

Alpha level was set at 0.05

Superscripts $(*, \#, \$)$ for a particular variable: Median values with different superscripts are significantly different; Median values with the same superscripts are not significantly different.

Key: NSEG $=$ Neck stabilization exercises group

NSDEG $=\quad$ Neck stabilization plus dynamic exercises group

$\mathrm{NDEG}=\quad$ Neck dynamic exercises group

$\mathrm{n} \quad \quad=$ Number of participants in the group

$\mathrm{H} \quad$ = Kruskal-Wallis value

IQR $\quad=\quad$ Inter-Quartile Range

\section{Discussion}

This study investigates the effects of stabilization and dynamic exercises on pain intensity, functional disability and fear avoidance beliefs. The age of the participants ranged from 22 to 67 years, an age range consistent with those of patients affected by neck pain in most epidemiological studies [7, 6, 22].

The results obtained in this study show that there were no significant differences in pain intensity, disability and fear avoidance beliefs. This implies that the three groups were comparable at the point of commencement of the programme. It can therefore be concluded that the results obtained at different time points in the course of this study could have been largely due to the effect of the various treatment interventions.

Stabilisation exercises significantly reduced pain intensity and enhanced functional ability in patients with non-specific neck pain. This finding is consistent with the results of previous studies on the effect of neck stabilisation exercises on nonspecific neck pain [23, 24, 25, 12].

The mechanism through which stabilization exercises reduce non-specific neck pain may be based on the belief that intense exercise increases activity in the motor pathways, thereby exerting an inhibitory effect on pain centres in the central nervous system. Furthermore, muscle contraction and strain on different connective tissues will stimulate the mechanoreceptors and increase sensory nerve activity, which in turn may inhibit the pathways mediating pain [26].

Barnhill [27] reported the interrelationship among neck pain and fear avoidance. Neck pain not only interferes with sleep and daytime functional activities but also affects the neurotransmitters in a person's brain responsible for sensory input processing and memory storage, thus changing the 
manner in which pain is perceived and dealt with. As a consequence, these patients often become depressed and/or anxious, in addition to the fact that the chronic symptoms of neck pain can lead patients to avoid social settings, favourite physical activity and even work or sex.

Ironically, because these patients had chronic pain they might have been taking pain medication which itself can contribute to depression. In addition, some of the pain drugs can cause nausea, which in turn cause appetite and loss of weight [27].

Since specific neck muscle dysfunction appears to be associated with pain and disability, exercises that will improve spinal stabilisation of the neck are used in the conservative management of neck pain to relieve pain. However, till date, evidence for the effectiveness of this approach is limited [25] only a few trials have shown evidence of its effectiveness. The problem with the previous trials is that they combined stabilisation exercises with other modalities. This study has provided proof for the theory that stabilisation exercises will be more effective than other exercise regimes in providing relief for patients with non-specific neck pain [25]. The results show the advantage of stabilisation exercises alone over a combination of stabilization and dynamic exercises, particularly as regards pain and improvement in functional disability scores over others groups. Stabilisation exercises showed improvements in pain intensity scores and reduction in functional disability scores even at week 4 of the study and especially at the week 8 .

Previous studies that were compared with this study combined neck stabilisation exercises with some physiotherapy treatments. The present study has provided more evidence to prove the effectiveness of stabilisation exercises without combining it with any exercises.

According to Ylinen [19], the mechanism by which the stabilization and dynamic exercises achieves its therapeutic effect on patients with non-specific neck pain is that the cervical muscles that tend to be weakened with neck pain are strengthened by strength or endurance exercises. The deep neck flexors and extensors scapular stabilizers and upper thoracic extensors are some of the muscles that are affected. Strengthening exercises for the shoulders and upper extremities reduce pain arising from the trapezius muscles and improved function as demonstrated by Ahlgren et al. [28] in a study evaluating the effects of 10 weeks of dynamic strength, endurance, and coordination exercises on pain and physical performance. The effects, however, had disappeared by the followup at 8 months [28].

Thera-band was used in the present study to add resistance in the dynamic exercise in sitting and standing positions in order to strengthen the weaker muscles, therefore bringing about stability of the muscles and spine. This procedure reduced pain and improved the functional ability of the patients. Also, a timing delay of the neck stabilizers occurs during arm motion, most noticeably the deep neck flexors compromising spinal control during upper extremity function [29]. Studies have shown a tendency toward over-activity in the upper trapezius muscle and anterior superficial neck muscles during repetitive arm activities and head lift with prolonged relaxation times post activity $[29,30]$.

This intervention probably works because exercise has both physical and mental benefits through its effects on numerous systems, such as the cardiovascular system, immune system, brain function, sleep, mood, and the musculoskeletal system. Exercise also increases flexibility and mobility of structures, improves muscle strength and endurance, increases the tensile strength of ligaments and capsule, amplifies strength and prevents injury of tendons and cartilage, and is also important for repair of these tissues, thereby relieves pain [31]. 
Strength exercises with thera-band as a load for resistance to strengthen muscles that may have been weakened as a result of inactivity due to pain, are equally as effective in reducing pain and disability. Strength exercises using added resistance like thera-band are reported to be more effective in regaining full strength and endurance [32]. Therefore, to optimize return of normal neck muscle function, strength exercises progressions should be included at some point in the treatment programme for non-specific neck pain.

The result seen in this study may be attributed to progressive resistance training programme in increasing the resistance to strengthen the muscles of the neck and upper limbs. Since pain is associated with muscle weakness and disability, with the strengthening of these muscles there will be a decrease in pain and disability, as seen from this study. However, in cases of more severe neck pain, higher load exercises, if done too early, tend to exacerbate the pain which would further inhibit normal muscle function [32].

A significant correlation has been found previously between fear-avoidance beliefs about physical activity and neck disability indices in subjects with chronic neck pain [33, 34]. Neck muscle training should therefore not only be viewed as a means to improve physical function. A painful condition may lead one to avoid activities that stress the neck. Advice, such as to move within the limits of pain, can increase disuse, even though the aim may be to encourage the subject to be more active. The neck rehabilitation programme in the present study sought to change this pattern. Training may be seen as part of a cognitive therapy seeking to facilitate the adoption of a more active lifestyle by subjects. The high-intensity exercises showed the subjects that it is possible to move and load the neck considerably more than is done in ordinary daily life without aggravating their painful condition. Moreover, feedback from the strength test results and improved function, presumably encouraged the subjects to continue training.
From the results, the neck stabilisation exercises group showed greater pain reduction, disability scores reduction and fear avoidance belief scores reduction, followed by the neck stabilisation plus dynamic exercises group and then the neck dynamic exercises group. In all the variables, at week 4 and 8 of the study, there were no significant differences between the neck stabilisation plus dynamic exercises group and the dynamic exercises group. This may not be unconnected with the time required for dynamic strength training to strengthen the muscles.

Dusunceli et al. [25], in a study on efficacy of neck stabilisation exercises for neck pain, compared three treatment protocols: physical therapy agent, physical therapy agent plus isometric and stretching exercises, and physical therapy plus stabilisation exercises. Dusunceli et al. [25] concluded that the stabilisation protocol and physical therapy agent for chronic neck pain patients were equally effective in reducing pain and neck disability index score.

Implications: Clinician should always prescribe stabilization exercises, or in combination with dynamic or dynamic alone for patients with non-specific neck pain. But stabilization exercises alone result in better clinical outcome than combination of both stabilization and dynamic or dynamic exercises alone.

Conclusion: Stabilization exercises alone as well as stabilization plus dynamic or dynamic exercises are effective in reducing pain, disability and fear avoidance beliefs. However stabilization exercises resulted in better reduction in pain intensity, functional disability and fear avoidance beliefs in participants with non-specific neck pain. 


\section{References:}

1. Siivola SM, Levoska S and Latvala K. Predictive factors for neck and shoulder pain: a longitudinal study in young adults. Spine ; 2004; 29: 1662-9.

2. Green BN. A literature review of neck pain associated with computer use: public health implications. Journal of Canadian Chiropractic Association 2008; 52:161-7.

3. Borghouts JA, Koes BW and Bouter LM. The clinical course and prognostic

factors of non-specific neck pain: A systematic review. Pain. 1998;77:1-33.

4. Cote P, Cassidy JD and Carroll L. The factors associated with neck pain and its related disability in the Saskatchewan population. Spine. 2000; 25: 1109-1117.

5. Fejer R, Kyvik $\mathrm{KO}$ and Hartvigsen J. The prevalence of neck pain in the world population: a systematic critical review of the literature. European Spine Journal. 2006; 15(6):834-48.

6. Adedoyin RA, Idowu BO, Adagunodo RE, Owoyomi AA and Idowu PA. Musculoskeletal Pain Associated with the Use of Computer systems in Nigeria. International Journal of pain, symptoms control and Palliative care 2004; 13(2): 125-130.

7. Ayanniyi O, Mbada CE and Oke A. M. Pattern and Management of Neck pain from cervical spondylosis in physiotherapy clinics in south West Nigeria. Journal of clinical sciences, 2007; 7(2): 1-5.

8. Ogwumike OO, Kaka B, Adeniyi FA, Fawole H.O and Idowu OA. Prevalence of neck pain in a rural community Nigeria. Journal of medicine and Biomedical research 2015; 14 (1): 104-116.

9. Lagattuta F and Falco F. Assessment and treatment of cervical spine disorders. Physical medicine and rehabilitation. 2nd edition. Braddom RL, eds Philadelphia: W.B.Saunders; P. 2000; 762-90.

10. Michaels E, Wolf MD, Lanry A Levies. Cervical radiculopathies; conservatives approach to management. Physical medicine and Rehabilitation clinics of North America 2002; 13: 589-608.

11. Waling K, Jarvholm B and Sundelin G. Effects of training on female trapezius myalgia: an intervention study with a 3-year followup. Spine. 2002;27:789-796.

12. Jull G, Trott $P$ and Potter $H$,. A randomized controlled trial of exercises and manipulative therapy for cervicogenic headache. Spine. 2002; 27: 1835-1843.

13. Kay TM, Gross A, Goldsmith C. Exercises for mechanical neck disorders.Cochrane Database of Systematic Reviews. 2012, 3, Article IDCD004250.

14. Provinciali L, Baroni M, Illuminati L and Ceravolo G. Multimodal treatment of whiplash injury. Scand Journal Rehabilitation Medicine. 1996 ; 28:105-11.

15. Koskimies K, Sutinen $\mathrm{P}$ and Aalto H. Postural stability, neck proprioception and tension neck. Acta Otolaryngology Supplement. 1997; 529: 95-7.

16. Flor H, Knost B and Birbaumer N. Processing of pain- and body-related verbal material in chronic pain patients: Central and peripheral correlates. Pain. 1997; 73:413-21.

17. Ylinen J, Takala EP, Nykanen MJ and Kautiainen HJ. Effects of twelve-month strength training subsequent to twelve-month stretching exercise in treatment of chronic neck pain. Journal of Strength and Conditioning Research. 2006; 20(2): 304-8.

18. Salo PK, Hakkinen AH, Kautiainen $H$ and Ylinen JJ. Effect of neck strength training on health related quality of life in females with chronic neck pain: a randomized controlled 1-year followup study. Health and Quality of life Outcomes. 2010, Retrieved on April 1, 2015 www.hqlo.com/ content/8/1/48. Dio: 10.1186/1477-75258-8-48.

19. Ylinen J, Takala EP and Nykanen M. Active neck muscle training in the treatment of chronic neck pain in women: a randomized controlled trial. The 
Journal of the American Medical Association. 2003; 289(19):2509-2516.

20. Delfino PD, Rampim DB, Alfleri FM, Tomikawa LCO, Fadel G, Stump PRNG, Imamura ST, Imamura $\mathrm{M}$ and Battistela LR. Neck pain: rehabilitation, Acta Fisiatr. 2012; 19: 73-81. Retrieved April 2, 2015 doi: 10.5935/01047795.20120014

21. Ekstrom RA, Donatelli RA and Soderberg GL. Surface electromyographic analysis of exercises for trapezius and serratus anterior muscles. Journal of Orthopaedic and Sports Physical Therapy 2003;33:5. Retrieved on April 2, 2015 www.jospt.org.

22. Taimela S, Takala EP, T Askl”of, K. Sepp“al“a, and S. Parviainen, Active treatment of chronic neck pain: a prospective randomized intervention. Spine. 2000; 25(8):1021-1027.

23. Griffiths C, Dziedzic K, J.Waterfield and J. Sim. Effectiveness of specific neck stabilization exercises or a general neck exercise program for chronic neck disorders: a randomized controlled trial. The Journal of Rheumatology. 2009; 36(2):390-397.

24. Nichol E. Neck stabilization exercises compared to physical therapy modarlities to decrease insidious neck pain in adults treated in an outpatient setting. PT Critical appraised topics. Paper 30 2012, Access online 14/ 2/2013 http://commons. pacificu.edu/ptcats $/ 30$.

25. Duncelli Y, Ozturk C, Atama F, and Durmav B. Efficacyof Neck Stabilisation exercises for Neck Pain: A Randomised Controlled Study. Journal of Rehabilitation Medicine. Review. 2009; 41:1-6.

26. Hides JA, Jull GA, Richardson CA. Long-term effects of specific stabilizing exercises for first-episode low back pain. Spine 2001; 26: E243-E248.

27. Barnhill F. The link between neck pain and depression 2009.[Internet] Updated 2014 December 05.Available from: http://www. everydayhealth.com/depression/is-depression- causing-your-neck-pain.aspx.

28. Ahlgren C, Waling K, Kadi F, Djupsjo“ Backa M, Thornell LE and Sundelin G. Effects on physical performance and pain from three dynamic training programs for women with work-related trapezius myalgia. Journal.of Rehabilitation. Medicine. $2001 ; 33: 162-169$.

29. Falla D, Jull G and Hodges P. Patients with neck pain demonstrate reduced electromyographic activity of the deep cervical flexor muscles during performance of the craniocervical flexion test. Spine 2004; 29:2108-2114.

30. Zito G, Jull G, Story I. Clinical tests of musculoskeletal dysfunction in the diagnosis of Cervicogenic headache. Manual Therapy. 2006; 11:118-129.

31. Zimmerman GL, Olsen CG and Bosworth MF. A. 'stages of change' approach to helping patients change behavior. American Family Physician; 2000; 61(5):1409-16.

32. Kennedy C. Exercise for mechanical neck pain. Chapter 13, 2011 Elsevier Ltd Doi 10.10616780-7020-3528-9000.3-3.

33. George SZ, Fritz JM and Erhard RE. A comparison of fear-avoidance beliefs in patients with lumbar spine pain and cervical spine pain. Spine 2000; 26:2139-2145.

34. Waddell C, Newton M and Henderson I. A FearAvoidance Beliefs Questionnaire (FABQ) and the role of fear-avoidance beliefs in chronic low back pain and disability. Pain. 1993; 52:157-168.

\section{Correspondence address:}

Bashir Kaka MSc PT

Department of Physiotherapy, Faculty of Allied Health Sciences, College of Health Sciences, Bayero University Kano, P.M.B 3011, Kano, Nigeria

Email: bkaka.pth@buk.edu.ng

Mobile phone number: +2348028460237 
